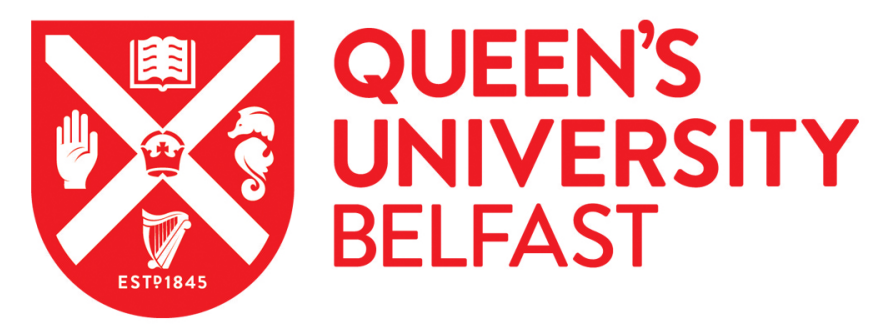

\title{
Exploring Turkish Mathematics Teachers' Content Knowledge of Quadrilaterals
}

Bütüner, S. Ö., \& Filiz, M. (2017). Exploring Turkish Mathematics Teachers' Content Knowledge of Quadrilaterals. International Journal of Research in Education and Science, 3(2), 395-408. https://doi.org/10.21890/ijres.327898

\section{Published in:}

International Journal of Research in Education and Science

\section{Document Version:}

Peer reviewed version

\section{Queen's University Belfast - Research Portal:}

Link to publication record in Queen's University Belfast Research Portal

\section{Publisher rights}

(C) 2017 International Journal of Research in Education and Science.

This work is made available online in accordance with the publisher's policies. Please refer to any applicable terms of use of the publisher.

\section{General rights}

Copyright for the publications made accessible via the Queen's University Belfast Research Portal is retained by the author(s) and / or other copyright owners and it is a condition of accessing these publications that users recognise and abide by the legal requirements associated with these rights.

Take down policy

The Research Portal is Queen's institutional repository that provides access to Queen's research output. Every effort has been made to ensure that content in the Research Portal does not infringe any person's rights, or applicable UK laws. If you discover content in the Research Portal that you believe breaches copyright or violates any law, please contact openaccess@qub.ac.uk. 


\title{
Exploring Turkish Mathematics Teachers' Content Knowledge of Quadrilaterals
}

\author{
Suphi Önder Bütüner, Mehmet Filiz
}

\begin{abstract}
The aim of this research was to examine mathematics teachers' performances in defining special types of quadrilaterals, identifying their family and hierarchically classifying them. In this vein, 33 of 58 primary school mathematics teachers working in the province of Yozgat, Turkey were voluntarily recruited for this survey, and they were asked to complete a data collection form consisting of three open-ended questions. In the first question, participants were asked to define the special types of quadrilaterals. In the second question, teachers were asked to recognise kites, trapezoids, parallelograms, rectangles and rhombuses among 15 quadrilaterals. Finally, participants were prompted to make a hierarchical classification of the special types of quadrilaterals. The results of this study illustrated that while 20 mathematics teachers could define a kite hierarchically, only 1 of the sample could hierarchically define a trapezoid. In addition, participants encountered difficulties not only in determining the kite and trapezoid family, but also in demonstrating the relations of kite-rhombus, trapezoid-parallelogram and trapezoid-rectangle quadrilaterals. Hence, in-service training programs for primary school mathematics teachers should be organized to improve content knowledge of geometry in general and quadrilaterals in particular.
\end{abstract}

Keywords: Quadrilaterals, Content knowledge, Hierarchical classification, Primary school mathematics teachers

\section{Introduction}

The National Council of Teachers of Mathematics (2000) reported that teachers should have deep knowledge and understanding of the subjects which they teach. Shulman (1986) claimed that this type of knowledge referred to content knowledge and argued that teachers' pedagogical knowledge is also crucial for effective teaching. Pedagogic knowledge spans the principles and strategies of classroom management and organization that are cross-curricular. Effective teachers possess subject-specific pedagogic knowledge, know their students, and use appropriate teaching materials and processes of teaching (Marks, 1990). On the other hand, Ball et al. (2005) asserted that content knowledge and pedagogic knowledge are distinctive, yet content knowledge is related to mathematical knowledge for teaching. Additionally, numerous studies have shown that students' mathematics competencies are closely associated with their teachers' knowledge of mathematics (Ball et al., 2005; DarlingHammond, 2000; Goldhaber \& Brewer, 2000; Hill et al., 2008; Morris, Hiebert, \& Spitzer, 2009).

In Turkey, the elementary school mathematics curriculum includes geometry but students' performance is seen as middling. In the Trends in International Mathematics and Science Study (TIMSS) 2015 report, Mullis et al. (2016) ranked the geometry achievement of students in 39 countries. Turkey was placed $22^{\text {nd }}$ in this index, with both male and female students performing slightly below world average. This finding suggests that local studies are necessary to monitor mathematics teachers' knowledge of Geometry and to identify where gaps can be addressed.

The topic of quadrilaterals is fundamental to the study of geometry and is therefore included in grades 6,7 and 8 of the mathematics curriculum in Turkey (T.C. Millî Eğitim Bakanlığı Talim ve Terbiye Kurulu Başkanlı̆̆ı, 2013). The topic is mostly taught in Turkey by providing information to students about the definitions and properties of the special types of quadrilaterals as well as relations between these quadrilaterals (Akkaş \& Türnüklü, 2015). Usiskin et al. (2008) indicated that the special types of quadrilaterals can be defined exclusively and inclusively. While an exclusive definition is true for a specific quadrilateral, an inclusive definition would be valid for a family of quadrilaterals. For instance, the exclusive definition of a trapezoid is a quadrilateral with only one pair of parallel sides whilst the inclusive definition of a trapezoid is a quadrilateral with at least one pair of parallel sides. The exclusive and inclusive definitions of a trapezoid also result in two different hierarchical classifications of quadrilaterals as seen in Figure 1.a and Figure 1.b, respectively (Popovic, 2012). Josefsson (2013) expressed that both definitions have limitations and benefits. The exclusive definition is useful when students are first shown the special types of quadrilaterals including a trapezoid or rhombus and taught their basic properties. On the other hand, the inclusive definition is beneficial when students proceed to higher levels of study. For example, when the inclusive definition of a trapezoid is learned, students realize that the properties of a trapezoid are also true for a parallelogram, rectangle, rhombus, and square. Thus, knowledge of the inclusive definition can be an advantage over the exclusive definition. 
Given the importance of the inclusive definition of quadrilaterals, the following section highlighted studies on exploring pre-service teachers' and mathematics teachers' knowledge of quadrilaterals.

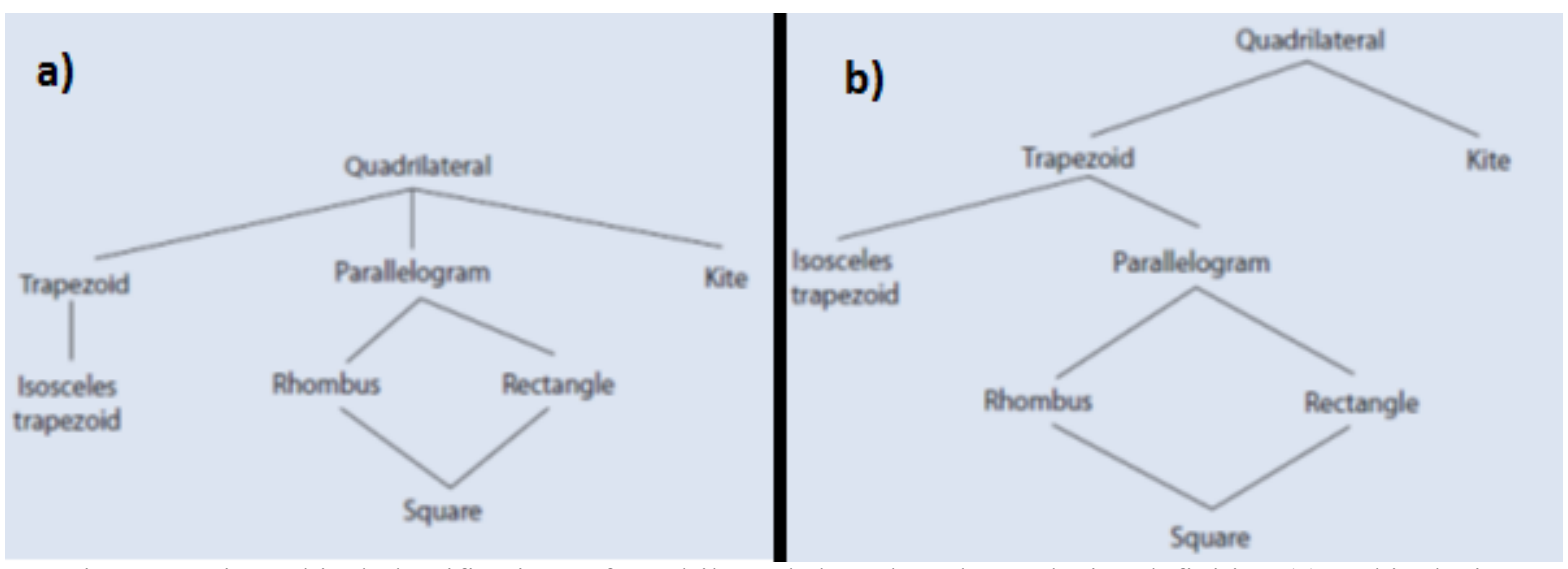

Figure 1. Hierarchical classifications of quadrilaterals based on the exclusive definition (a) and inclusive definition (b) of quadrilaterals (Popovic, 2012)

\section{Literature review of studies on quadrilaterals}

Fujita and Jones (2007) performed two studies to investigate not only how pre-service teachers define a trapezium, parallelogram, rectangle and square, but also how well they demonstrate relations among them. 158 pre-service teachers participated in the first study and were asked to determine whether a square is a trapezium, a square is a rectangle, and a parallelogram is a trapezium as well as define the so-called types of quadrilaterals. It was found that 14 pre-service teachers $(8.9 \%)$ indicated that a square is a trapezium; $29(18.4 \%)$ that a parallelogram is a trapezium; and $20(12.7 \%)$ that a square is a rectangle. Additionally, $19(12 \%), 93(58.9 \%), 34(21.5 \%)$ and 60 (38\%) pre-service teachers correctly defined a trapezium, parallelogram, rectangle and square, respectively. In the second study, 105 pre-service teachers were asked to define a parallelogram and recognise parallelograms among a collection of 15 quadrilaterals. While 86 pre-service teachers (82\%) almost accurately defined a parallelogram, only $21(20 \%)$ could correctly identify parallelograms among 15 quadrilaterals.

Çontay and Paksu (2012) examined pre-service mathematics teachers' understandings of the relations between a kite and square. They asked five pre-service mathematics teachers (PT1, PT2, PT3, PT4 and PT5) to classify a set of quadrilaterals (two non-specific quadrilaterals, a kite, trapezoid, parallelogram, rectangle and square) as a kite or none-kite. Afterwards, individual interviews were conducted to explore teachers' reasoning for their classifications. Teachers PT1, PT2, PT3 and PT5 accurately categorised the given quadrilaterals, while PT4 indicated that a square is not a kite, yet a trapezoid and one of the non-specific quadrilaterals are a kite. During the individual interview stage, PT1 elected to place a square in the non-kite category as they were unable to explain why it was necessary to include a square in the kite category. Consequently, only three of the five pre-service mathematics teachers could demonstrate an understanding of the relations between kite and square.

Türnüklü, Akkaş, et al. (2013) determined how 9 primary school mathematics teachers hierarchically organise the special types of quadrilaterals: trapezium, parallelogram, rectangle, rhombus and square. They found that 3 teachers (T1, T2 and T5) could not hierarchically classify the given quadrilaterals, 2 teachers (T4 and T7) chose to tabulate these quadrilaterals based on their different and common properties, and 2 teachers (T3 and T8) hierarchically organised these quadrilaterals according to their length of sides. Therefore, they revealed that a square is the special case of a rhombus, and a rectangle is the special case of a parallelogram. On the other hand, they did not express that a square is the special case of a rectangle, and a rhombus is the special case of a parallelogram. Teacher (T9) hierarchically classified the given quadrilaterals based on their angles and reported that a square is the special case of a rectangle, and a rhombus is the special case of a parallelogram. However, T9 did not mention that a square is the special case of a rhombus, and a rectangle is the special case of a parallelogram. Teacher (T6) stated that a parallelogram, rectangle, rhombus and square are the special cases of a trapezoid, and a rectangle, rhombus and square are the special cases of a parallelogram. However, T6 did not indicate that a square is the special case of a rhombus. 
Erdogan and Dur (2014) investigated 57 pre-service high school mathematics teachers' ability to define a trapezoid, parallelogram, rectangle, rhombus and square, identify the parallelogram, rhombus, rectangle and square families among a set of 15 quadrilaterals, and to make a hierarchical classification of a kite, trapezoid, parallelogram, rectangle, rhombus and square. They reported that 26 pre-service high school mathematics teachers $(46 \%)$ correctly stated the definition of a trapezoid. Most of the sample $55(96 \%)$ provided the correct definition of a parallelogram but only half (51\%) detected the parallelogram family. Similarly, $55(96 \%)$ accurately defined a rectangle while only $26(46 \%)$ recognised the rectangle family. Only 19 of the pre-service high school mathematics teachers (33\%) could correctly indicate the definition of a rhombus. Only $28(49 \%)$ determined the rhombus family. Most (95\%) could provide the correct definition of a square and $48(84 \%)$ detected the square family. However in terms of the hierarchical classification of quadrilaterals, only $23(40 \%)$ of the sample correctly demonstrated the hierarchical relations among a parallelogram, rectangle, rhombus and square, and only 4 of those accurately included a trapezoid in their diagrams.

Pickreign (2007) asked 40 pre-service teachers to define a rectangle and rhombus. It was found that while 39 preservice teachers $(98 \%)$ try defining a rectangle, only 9 of those correctly provide the hierarchical definition of a rectangle which includes a square, yet excludes a parallelogram. While 29 pre-service teachers $(73 \%)$ attempted to define a rhombus only one of them accurately gave the hierarchical definition of a rhombus which contains a square, but excludes a parallelogram.

Shir ve Zaslavsky (2001) requested 20 elementary school mathematics teachers to detect the accurateness of eight different definitions of a square. Teachers first reviewed the given definitions and chose the correct definition from among those provided. Afterwards, groups of 3-5 mathematics teachers compared and discussed their responses. They found that only five teachers could determine that all of the definitions they were presented with were correct.

\section{The aim of this study}

The previous literature review section illustrated that:

- Individuals' knowledge of quadrilaterals can be detected by asking them to define quadrilaterals, determine their family and make a hierarchical classification of them.

- Turkish pre-service mathematics teachers encounter problems in defining quadrilaterals, determining their family and hierarchically organizing them.

- A limited number of studies have been conducted to determine Turkish mathematics teachers' content knowledge of quadrilaterals.

In this regard, this study aimed to further investigate and determine mathematics teachers' content knowledge of quadrilaterals.

\section{Methodology}

In this study, mathematics teachers' ability to define quadrilaterals, recognising their family and hierarchically classifying them were examined via a survey method which allows researchers to explore the phenomena which have already taken place (Çepni, 2014; DePoy \& Gitlin, 2011).

After creating a data collection tool based on previous studies (Erdogan \& Dur, 2014; Fujita \& Jones, 2007), all required permissions to perform this research were obtained from Yozgat governorship, Turkey. Thereafter, all elementary school principals in Yozgat were informed about this study and meetings arranged with School principals and 58 elementary school mathematics teachers to introduce the research.

\section{Participants}

To recruit participants, convenience sampling method was used in this study. In this method, researchers determine a set of inclusion and exclusion criteria. Then, those meeting these criteria are asked to voluntarily participate in the research (DePoy \& Gitlin, 2011). In this vein, this research was presented to 58 elementary school mathematics teachers in Yozgat, and 33 of those consented to enrol in this study. 
As illustrated in Figure 2.a, there were 19 female and 14 male participants and their mathematics teaching experience varied from 1 to 17 years with a mean of 10 years. As seen in Figure 2.b, 7 teachers had worked for 5 or fewer years, 9 had taught mathematics for 6 to 10 years, 12 for 11 to 15 years, and 5 possessed 16 or more years experience.

Generalizations from convenience sampling method is arguable due to the representativeness issue. (Beins \& McCarthy, 2011; L. Cohen, Manion, \& Morrison, 2013). On the other hand, this study is considered representative of elementary school mathematics teachers in Yozgat province where this research was conducted, as 58\% of local teachers elected to take part and participants' maths teaching experience ranged between one and seventeen years (Can, 2014; L. Cohen et al., 2013).

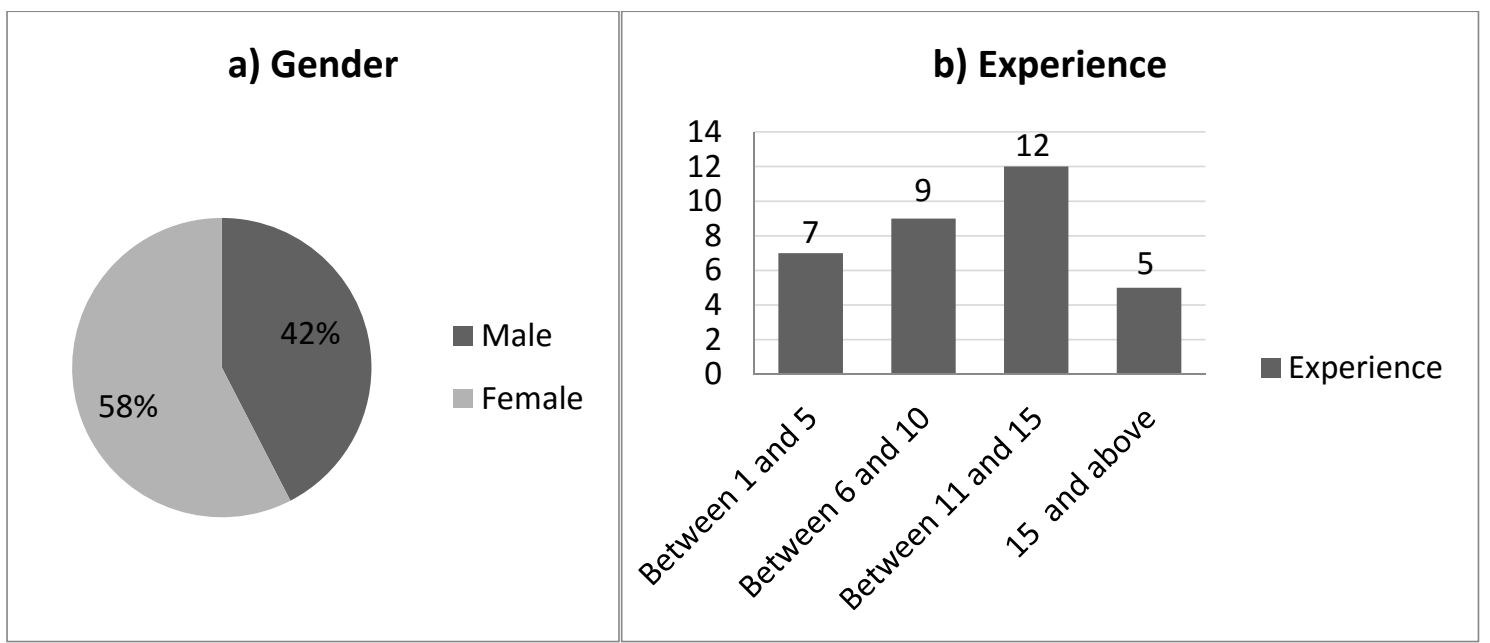

Figure 1. Demographics of participants by gender (a) and experience (b)

\section{Data collection tool and data analysis}

The question form of this research consisted of three open-ended questions which were adapted from previous studies (Erdogan \& Dur, 2014; Fujita \& Jones, 2007).

In the first question, mathematics teachers were given a set of special types of quadrilaterals (kite, trapezoid, parallelogram, rectangle, rhombus and square), and they were asked to define these quadrilaterals. Teachers' answers to the first question were classified as erroneous, prototype or hierarchical definitions. These categories and their descriptions were inspired by Cansız-Aktaş (2016), Fujita (2012), Fujita and Jones (2007) and Pickreign (2007). As demonstrated in Figure 3, any definition is first evaluated as to whether it is true for the prototype of the given quadrilateral. If it is not, this definition is categorised as an erroneous definition. Otherwise, the definition might be either a prototype or hierarchical definition. Then, the validity of the definition is assessed for the special cases of the given quadrilateral (see Table 1). Here an invalid definition is categorised as a prototype definition, and a valid definition is called a hierarchical definition. To illustrate, "a kite has two pairs of adjacent equal sides and the sum of the size of opposite angles is 180" is an example of an erroneous definition, for the sum of the size of opposite angles in kites is not always 180. Another definition might be "a kite is made up of two different isosceles triangles joined base to base", and this definition is categorised as a prototype definition, since this definition is not true for a rhombus and square which are formed by joining two identical isosceles triangles base to base. However, a hierarchical definition of a kite can be "a kite contains two isosceles triangles that share a common base", because this definition is true not only for a kite but for also a rhombus and square. 


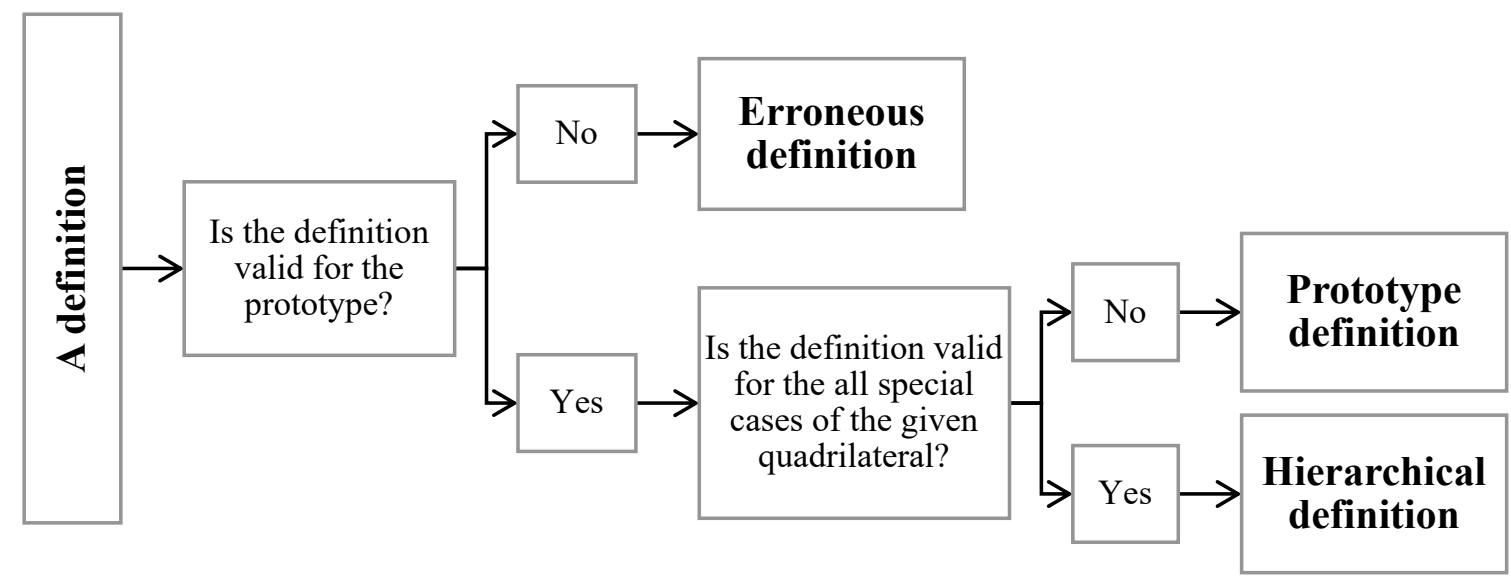

Figure 2. A flowchart for analysing mathematics teachers' definitions of quadrilaterals

Table 1. Special types of quadrilaterals with their special cases (adapted from Usiskin et al., 2008)

\begin{tabular}{ll}
\hline Special types of quadrilaterals & Their special cases \\
\hline Kite & Rhombus, square \\
Trapezoid & Parallelogram, rectangle, rhombus, square \\
Parallelogram & Rectangle, rhombus, square \\
Rectangle & Square \\
Rhombus & Square \\
Square & Not Available \\
\hline
\end{tabular}

In the second question, mathematics teachers were shown Figure 4 and requested to identify all kites, trapezoids, parallelograms, rectangles and rhombuses. For analysis, one point and two points were first given for each prototype and special case, respectively as shown in Table 2. Then, every teacher's total point score for each quadrilateral was computed. Next, the ratio of their total points score for each quadrilateral to the total possible points they could score plus the number of their erroneous answers was calculated. For instance, " $2,4,7,11,13$, 15 " might be a teacher's answer to recognizing rectangles among quadrilaterals in the second question. For this answer, the teacher's total point score is computed as 5, with 3 of the points awarded for identifying the prototypes of a rectangle (" $2,7,13$ ”), and a further 2 points for noting the special case of a rectangle (11). As 15 is neither the prototype or special case of a rectangle, it is scored as an erroneous answer. Thus, the ratio of the teacher's total points ( 5 points) to the total possible points ( 7 points) plus the number of their erroneous answers ( 1 point) is equal to $5 / 8$ for recognising rectangles. 


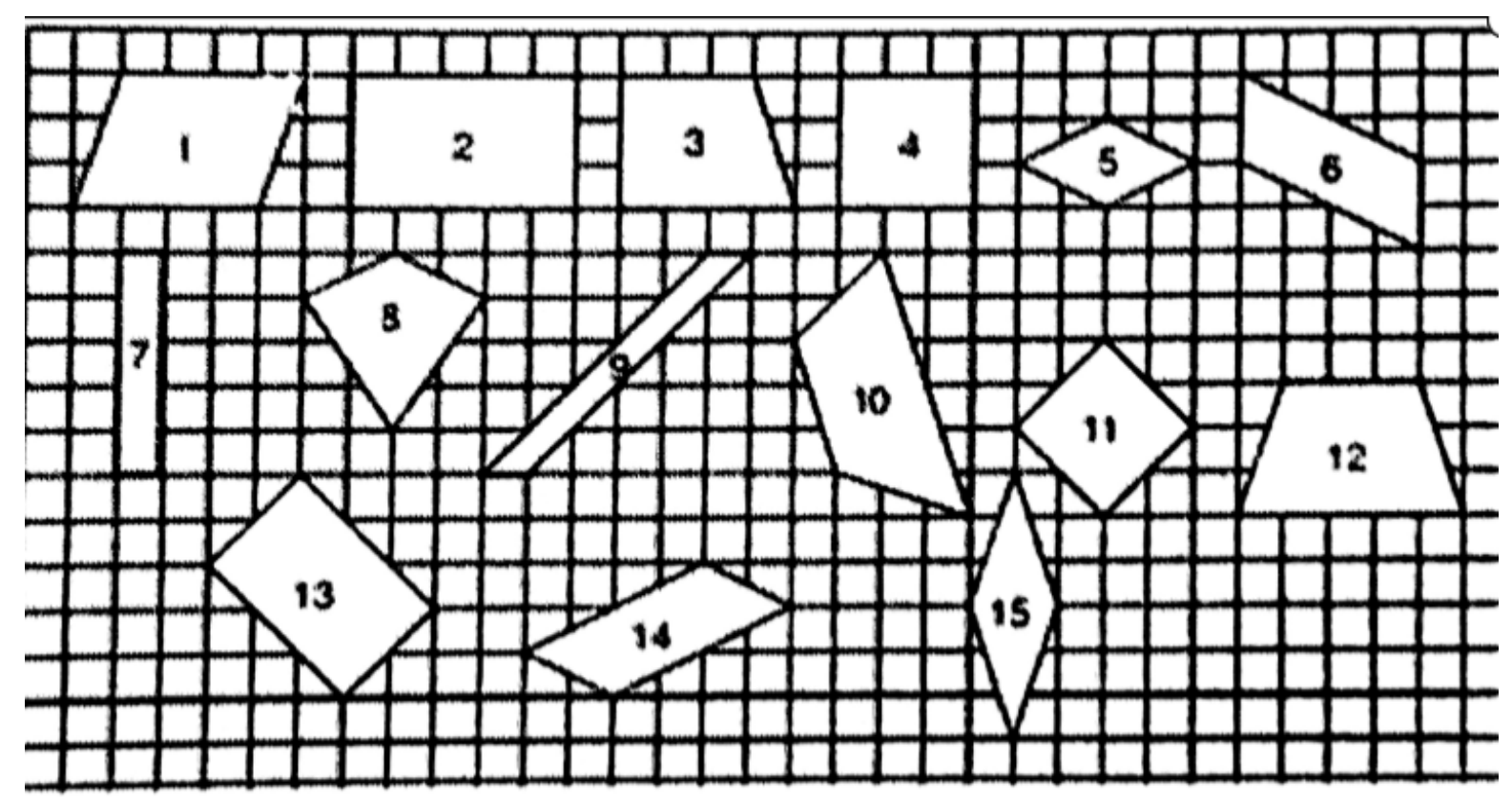

Figure 3. Given quadrilaterals in the second question

Table 2. Special types of quadrilaterals with their special cases in the second question

\begin{tabular}{llll}
\hline Quadrilaterals & $\begin{array}{l}1 \text { point for each } \\
\text { prototype }\end{array}$ & 2 points for each special case & $\begin{array}{l}\text { Total } \\
\text { points }\end{array}$ \\
\hline Kites & 8 & $4,5,11,15$ & $9(=1 \times 1+2 \times 4)$ \\
Trapezoids & $3,10,12$ & $1,2,4,5,6,7,9,11,13,14,15$ & $25(=1 \times 3+2 \times 11)$ \\
Parallelograms & $1,6,9,14$ & $2,4,5,7,11,13,15$ & $18(=1 \times 4+2 \times 7)$ \\
Rectangles & $2,7,13$ & 4,11 & $7(=1 \times 3+2 \times 2)$ \\
Rhombuses & 5,15 & 4,11 & $6(=1 \times 2+2 \times 2)$ \\
\hline
\end{tabular}

In the last question, the same set of special types of quadrilaterals as in the first question was given to mathematics teachers, yet they were asked to classify these quadrilaterals hierarchically and show these hierarchical relationships in a knowledge map. Knowledge maps in this study were evaluated by using the similarity index which is equal to the ratio of the number of common links in two knowledge maps to the number of links in both knowledge maps (Goldsmith, Johnson, \& Acton, 1991). According to Kudikyala and Vaughn (2004), the level of similarity between two knowledge maps can be little, moderate and strong where the cut-off values are .4 and.7. On the other hand, Sarwar and Trumpower (2015) argued that these cut-off values are reasonable for novice learners, but not experts. Hence, the cut-off values in this study were assumed to be .50 and .75 for moderate and strong similarity, respectively. As an example, the referent knowledge map, which was adapted from Usiskin et al. (2008), and an example of a teacher's knowledge map are illustrated in Figure 5.a and Figure 5.b, respectively. The number of common links between two knowledge maps (relevant links) is 6. Additionally, while the number of unique links in the referent map (missing links) is 1, the number of unique links in the teacher's knowledge map (extraneous links) is 2. Thus, the similarity index is equal to the ratio of 6 to 9 which corresponds to a moderate similarity. 
a) Referent knowledge map

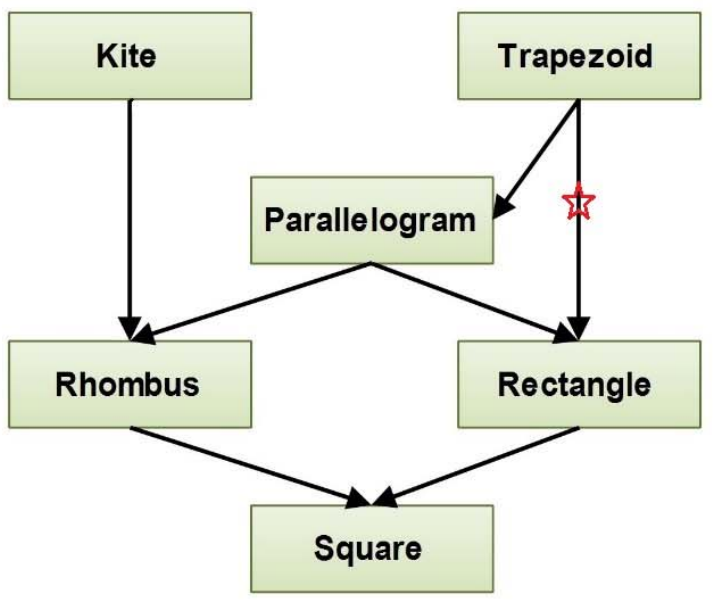

b) An example of a teacher's knowledge map

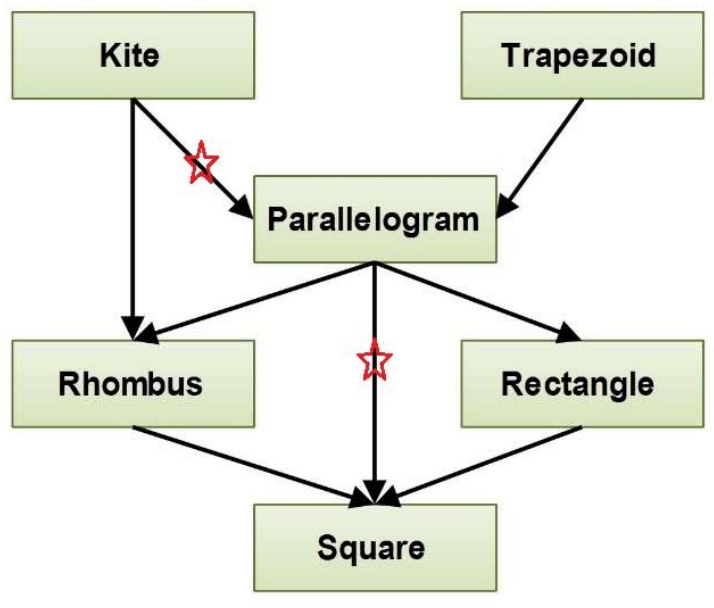

Figure 4. Referent knowledge map (a) and an example of a teacher's knowledge map (b)

Before identifying the aforementioned evaluation criteria for each question, two researchers conducted the literature review on how these questions had been analysed in previous studies. Afterwards, they had a few online meetings in which different approaches for evaluating each question item were compared and identified as the most suitable evaluation criterion for each question. Thereafter, two researchers independently categorised teachers' answers to each question based on the corresponding evaluation criteria. Next, their coding were compared, and Cohen's kappa coefficient was computed as 0.90 indicating that the inter-rater agreement was almost perfect because it is between 0.81 and 1.00 (J. Cohen, 1960; Gwet, 2014; Landis \& Koch, 1977). Discrepancies were reviewed and reconciled through consensus. Finally, the frequencies of the resultant codes were illustrated in the tables.

\section{Findings}

In the first question, mathematics teachers were asked to define a few special types of quadrilaterals including a kite, trapezoid, parallelogram, rectangle, rhombus and square. As demonstrated in Table 3, 20 teachers $(60 \%)$ hierarchically defined a kite whilst 11 teachers $(33 \%)$ provided the prototype definition of a kite. In terms of trapezoid definition, only 3 teachers $(9 \%)$ gave a hierarchical definition while 30 teachers $(91 \%)$ gave a prototype one. For parallelogram and rectangle, 31 teachers (94\%) offered a hierarchical definition, while 1 teacher (3\%) and 2 teachers $(6 \%)$ stated a prototype definition of a parallelogram and rectangle, respectively. For rhombus, 26 teachers $(79 \%)$ hierarchically defined it and $5(15 \%)$ expressed a prototype definition. Teachers were not asked to classify squares as they appear at the base of the hierarchy of quadrilaterals. Instead, researchers were concerned with the correctness of each definition of a square provided. All teachers $(33 ; 100 \%)$ could accurately define a square but they chose to emphasise different characteristics, for instance, a few teachers mentioned that a square is a special case of a rectangle. 
Table 3. Mathematics teachers' definitions of special types of quadrilaterals

\begin{tabular}{|c|c|c|c|}
\hline $\begin{array}{l}\text { The name of } \\
\text { quadrilaterals }\end{array}$ & $\begin{array}{l}\text { The classification of } \\
\text { definitions }\end{array}$ & Frequencies & Examples \\
\hline \multirow[t]{3}{*}{ Kite } & Hierarchical & 20 & $\begin{array}{l}\text { is a quadrilateral formed with two isosceles triangles } \\
\text { sharing a common base. }\end{array}$ \\
\hline & Prototype & 11 & $\begin{array}{l}\text { is a quadrilateral formed with two different isosceles } \\
\text { triangles joined base to base. }\end{array}$ \\
\hline & Erroneous or partial & 2 & $\begin{array}{l}\text { is a quadrilateral which has two pairs of equal sides, } \\
\text { and the sum of its opposite angles is } 180 \text {. }\end{array}$ \\
\hline \multirow[t]{3}{*}{ Trapezoid } & Hierarchical & 3 & $\begin{array}{l}\text { is a quadrilateral having at least a pair of parallel } \\
\text { sides. }\end{array}$ \\
\hline & Prototype & 30 & $\begin{array}{l}\text { is a quadrilateral having only one pair of parallel } \\
\text { sides. }\end{array}$ \\
\hline & Erroneous or partial & 0 & \\
\hline \multirow[t]{3}{*}{ Parallelogram } & Hierarchical & 31 & $\begin{array}{l}\text { is a quadrilateral whose both opposite sides are } \\
\text { parallel, and opposite angles are equal. }\end{array}$ \\
\hline & Prototype & 1 & $\begin{array}{l}\text { is a quadrilateral whose both opposite sides are } \\
\text { parallel, and its diagonals bisect each other, yet the } \\
\text { angle between these diagonals is not } 90 \text {. }\end{array}$ \\
\hline & Erroneous or partial & 1 & $\begin{array}{l}\text { is a quadrilateral whose opposite angles are equal, } \\
\text { and the size of its opposite sides are same. }\end{array}$ \\
\hline \multirow[t]{3}{*}{ Rectangle } & Hierarchical & 31 & $\begin{array}{l}\text { is a quadrilateral whose opposite sides are equal, and } \\
\text { the size of its angles is } 90 .\end{array}$ \\
\hline & Prototype & 2 & $\begin{array}{l}\text { is a quadrilateral having a pair of equal short parallel } \\
\text { sides and a pair of equal long parallel sides as well as } \\
\text { the size of its angles is } 90 \text {. }\end{array}$ \\
\hline & Erroneous or partial & 0 & \\
\hline \multirow[t]{3}{*}{ Rhombus } & Hierarchical & 26 & is a parallelogram whose all sides are equal. \\
\hline & Prototype & 5 & $\begin{array}{l}\text { is a quadrilateral whose all sides are equal, and the } \\
\text { sizes of its opposite angles are same, but none of them } \\
\text { is equal to } 90 \text {. }\end{array}$ \\
\hline & Erroneous or partial & 2 & is a quadrilateral whose all sides are equal. \\
\hline \multirow[t]{2}{*}{ Square } & Accurate & 33 & $\begin{array}{l}\text { is a rectangle whose sides are equal, and the size of } \\
\text { its angles is } 90 . \\
\text { is a quadrilateral whose sides are equal, its opposite } \\
\text { sides are parallel, and the size of its angles is } 90 \text {. }\end{array}$ \\
\hline & Erroneous or partial & 0 & \\
\hline
\end{tabular}

In the second question, mathematics teachers were given 15 quadrilaterals and asked to recognise kites, trapezoids, parallelograms, rectangles and rhombuses among them. As seen in Table 4, while 4 teachers (12\%) could identify the kite family, 21 (64\%) could only recognise prototypes of a kite. Similarly, in the trapezoid family, 4 teachers $(12 \%)$ observed the relations, while 22 teachers (67\%) could only find the prototypes. For parallelograms, 15 teachers $(45 \%)$ identified the family, and $11(33 \%)$ only prototypes. For rectangles, 14 teachers $(42 \%)$ determined the family, and 12 teachers $(36 \%)$ recognized only prototypes. In the rhombus case 16 teachers $(48 \%)$ indicated the rhombus family, while $9(27 \%)$ discovered only the prototypes. Consequently, mathematics teachers' average scores for this question were low. As illustrated in Figure 6, the mean scores obtained by 15 teachers $(45 \%)$ were found lower than .50, $10(30 \%)$ were computed between .50 and .74, $8(24 \%)$ were calculated as .75 or above, and only three of the participants $(9 \%)$ scored .95 or above. 
Table 4. Discrepancies between mathematics teachers' answers and the evaluation criteria

\begin{tabular}{|c|c|c|c|c|c|c|c|c|c|c|c|}
\hline & Kite & & Trapezo & & Parallelog & $\mathrm{ram}$ & Recta & & Rhombus & & Mean \\
\hline & Dis. & Sco & Dis. & Sco. & Dis. & Sco. & Dis. & Sco & Dis. & Sco & \\
\hline $\mathrm{T} 1$ & 4,5 & $5 / 9$ & - & $\begin{array}{l}25 / 2 \\
5\end{array}$ & 7 & $16 / 18$ & $\begin{array}{l}\text { "7", } \\
\text { "13" }\end{array}$ & $5 / 7$ & 4 & $4 / 6$ & 0.77 \\
\hline $\mathrm{T} 2$ & 4,5 & $5 / 9$ & - & $\begin{array}{l}25 / 2 \\
5\end{array}$ & 4,7 & $14 / 18$ & $\begin{array}{l}\text { "7", } \\
\text { "13" }\end{array}$ & $5 / 7$ & 4 & $4 / 6$ & 0.74 \\
\hline $\mathrm{T} 3$ & NSC & $1 / 9$ & $\begin{array}{l}\text { "12"; } \\
\text { NSC }\end{array}$ & $2 / 25$ & - & $18 / 18$ & - & $7 / 7$ & - & $6 / 6$ & 0.64 \\
\hline $\mathrm{T} 4$ & $\begin{array}{l}4,5, \\
11\end{array}$ & $3 / 9$ & $\begin{array}{l}\text { “3”; } 1 \\
2,4,5, \\
6,7 \\
11,13, \\
14,15\end{array}$ & $4 / 25$ & $\begin{array}{l}\text { "6", "9"; } \\
15\end{array}$ & $14 / 18$ & NSC & $3 / 7$ & 4 & $4 / 6$ & 0.47 \\
\hline T5 & $-;(1)$ & $\begin{array}{l}9 / 1 \\
0\end{array}$ & $\begin{array}{ll}9, & 11 \\
13, & 14 \\
15 & \end{array}$ & $\begin{array}{l}15 / 2 \\
5\end{array}$ & - & $18 / 18$ & $\begin{array}{l}\text { "13"; } \\
11\end{array}$ & $4 / 7$ & $" 15 "$ & $5 / 6$ & 0.78 \\
\hline T6 & NSC & $1 / 9$ & NSC & $3 / 25$ & - & $18 / 18$ & - & $7 / 7$ & - & $6 / 6$ & 0.65 \\
\hline $\mathrm{T} 7$ & $\mathrm{NSC}$ & $1 / 9$ & $\mathrm{NSC}$ & $3 / 25$ & - & $18 / 18$ & - & $7 / 7$ & - & $6 / 6$ & 0.65 \\
\hline T8 & $\mathrm{NSC}$ & $1 / 9$ & $\mathrm{NSC}$ & $3 / 25$ & - & $18 / 18$ & 4 & $5 / 7$ & - & $6 / 6$ & 0.59 \\
\hline T9 & - & $9 / 9$ & NSC & $3 / 25$ & - & $18 / 18$ & - & $7 / 7$ & - & $6 / 6$ & 0.82 \\
\hline $\begin{array}{l}\mathrm{T} 1 \\
0\end{array}$ & - & $9 / 9$ & - & $\begin{array}{l}25 / 2 \\
5\end{array}$ & - & $18 / 18$ & - & $7 / 7$ & - & $6 / 6$ & 1.00 \\
\hline $\begin{array}{l}\mathrm{T} 1 \\
1\end{array}$ & NSC & $1 / 9$ & NSC & $3 / 25$ & NSC & $4 / 18$ & NSC & $3 / 7$ & 4 & $4 / 6$ & 0.31 \\
\hline $\begin{array}{l}\mathrm{T} 1 \\
2\end{array}$ & NSC & $1 / 9$ & NSC & $3 / 25$ & NSC & $4 / 18$ & - & $7 / 7$ & NSC & $2 / 6$ & 0.36 \\
\hline $\begin{array}{l}\mathrm{T} 1 \\
3\end{array}$ & NSC & $1 / 9$ & NSC & $3 / 25$ & - & $18 / 18$ & - & $7 / 7$ & - & $6 / 6$ & 0.65 \\
\hline $\begin{array}{l}\mathrm{T} 1 \\
4\end{array}$ & NSC & $1 / 9$ & NSC & $3 / 25$ & NSC & $4 / 18$ & NSC & $3 / 7$ & - & $6 / 6$ & 0.38 \\
\hline $\begin{array}{l}\mathrm{T} 1 \\
5\end{array}$ & NSC & $1 / 9$ & NSC & $3 / 25$ & $\begin{array}{l}2,5,7 \\
13,15\end{array}$ & $8 / 18$ & NSC & $3 / 7$ & NSC & $2 / 6$ & 0.29 \\
\hline $\begin{array}{l}\mathrm{T} 1 \\
6\end{array}$ & $\mathrm{NSC}$ & $1 / 9$ & $\mathrm{NSC}$ & $3 / 25$ & NSC & $4 / 18$ & $\begin{array}{l}\text { "7"; } \\
\text { NSC }\end{array}$ & $2 / 7$ & $\begin{array}{l}\text { “5”, “15”; NSC; } \\
(1),(6),(13),(14)\end{array}$ & $\begin{array}{l}0 / 1 \\
0\end{array}$ & 0.18 \\
\hline $\begin{array}{l}\mathrm{T} 1 \\
7\end{array}$ & $\mathrm{NSC}$ & $1 / 9$ & $\mathrm{NSC}$ & $3 / 25$ & $\mathrm{NSC}$ & $4 / 18$ & - & $7 / 7$ & NSC & $2 / 6$ & 0.36 \\
\hline $\begin{array}{l}\mathrm{T} 1 \\
8\end{array}$ & NSC & $1 / 9$ & $\mathrm{NSC}$ & $3 / 25$ & NSC & $4 / 18$ & $\mathrm{NSC}$ & $3 / 7$ & - & $6 / 6$ & 0.38 \\
\hline $\begin{array}{l}\mathrm{T} 1 \\
9\end{array}$ & NSC & $1 / 9$ & NSC & $3 / 25$ & $\begin{array}{l}2,4,7 \\
11,13\end{array}$ & $8 / 18$ & - & $7 / 7$ & - & $6 / 6$ & 0.54 \\
\hline $\begin{array}{l}\mathrm{T} 2 \\
0\end{array}$ & NSC & $1 / 9$ & $\mathrm{NSC}$ & $3 / 25$ & NSC & $4 / 18$ & $\mathrm{NSC}$ & $3 / 7$ & - & $6 / 6$ & 0.38 \\
\hline $\begin{array}{l}\mathrm{T} 2 \\
1\end{array}$ & $\mathrm{NSC}$ & $1 / 9$ & $\mathrm{NSC}$ & $3 / 25$ & - & $18 / 18$ & - & $7 / 7$ & - & $6 / 6$ & 0.65 \\
\hline $\begin{array}{l}\mathrm{T} 2 \\
2\end{array}$ & $\mathrm{NSC}$ & $1 / 9$ & $\mathrm{NSC}$ & $3 / 25$ & - & $18 / 18$ & - & $7 / 7$ & NSC & $2 / 6$ & 0.51 \\
\hline $\begin{array}{l}\mathrm{T} 2 \\
3\end{array}$ & $\begin{array}{l}\text { NSC; } \\
(10)\end{array}$ & $\begin{array}{l}1 / 1 \\
0\end{array}$ & $\begin{array}{l}\text { "10"; } \\
\text { NSC }\end{array}$ & $2 / 25$ & NSC & $4 / 18$ & NSC & $3 / 7$ & NSC & $2 / 6$ & 0.23 \\
\hline $\begin{array}{l}\mathrm{T} 2 \\
4\end{array}$ & - & $9 / 9$ & NSC & $3 / 25$ & - & $18 / 18$ & - & $7 / 7$ & - & $6 / 6$ & 0.82 \\
\hline $\begin{array}{l}\mathrm{T} 2 \\
5\end{array}$ & NSC & $1 / 9$ & $\begin{array}{l}1,2,5 \\
6,7,9 \\
13,14 \\
15\end{array}$ & $7 / 25$ & NSC & $4 / 18$ & NSC & $3 / 7$ & NSC & $2 / 6$ & 0.28 \\
\hline $\begin{array}{l}\mathrm{T} 2 \\
6\end{array}$ & 4 & $7 / 9$ & $-;(8)$ & $\begin{array}{l}25 / 2 \\
6 \\
\end{array}$ & - & $18 / 18$ & - & $7 / 7$ & - & $6 / 6$ & 0.95 \\
\hline
\end{tabular}




\begin{tabular}{|c|c|c|c|c|c|c|c|c|c|c|c|}
\hline & \multicolumn{2}{|l|}{ Kite } & \multicolumn{2}{|c|}{ Trapezoid } & \multicolumn{2}{|c|}{ Parallelogram } & \multicolumn{2}{|c|}{ Rectangle } & \multicolumn{2}{|l|}{ Rhombus } & \multirow[t]{2}{*}{ Mean } \\
\hline & Dis. & Sco & Dis. & Sco. & Dis. & Sco. & Dis. & Sco & Dis. & Sco & \\
\hline $\begin{array}{l}\text { T2 } \\
7\end{array}$ & $\overline{\mathrm{NSC}}$ & $1 / 9$ & $\overline{\mathrm{NSC}}$ & $3 / 25$ & $\overline{\mathrm{NSC}}$ & $4 / 18$ & $\overline{\mathrm{NSC}}$ & $3 / 7$ & $\overline{\mathrm{NSC}}$ & $2 / 6$ & 0.24 \\
\hline $\begin{array}{l}\mathrm{T} 2 \\
8\end{array}$ & NSC & $1 / 9$ & NSC & $2 / 25$ & 13 & $16 / 18$ & NSC & $3 / 7$ & NSC & $2 / 6$ & 0.37 \\
\hline $\begin{array}{l}\text { T2 } \\
9\end{array}$ & NSC & $1 / 9$ & NSC & $3 / 25$ & NSC & $4 / 18$ & NSC & $3 / 7$ & 4 & $4 / 6$ & 0.31 \\
\hline $\begin{array}{l}\text { T3 } \\
0\end{array}$ & NSC & $1 / 9$ & NSC & $3 / 25$ & - & $18 / 18$ & - & $7 / 7$ & NSC & $2 / 6$ & 0.51 \\
\hline $\begin{array}{l}\text { T3 } \\
1\end{array}$ & 4 & $7 / 9$ & NSC & $3 / 25$ & - & $18 / 18$ & "13" & $6 / 7$ & - & $6 / 6$ & 0.75 \\
\hline $\begin{array}{l}\text { T3 } \\
2\end{array}$ & 4,11 & $5 / 9$ & NSC & $3 / 25$ & $5,11,13$ & $12 / 18$ & NSC & $3 / 7$ & "5", "15"; 4 & $2 / 6$ & 0.42 \\
\hline $\begin{array}{l}\text { T3 } \\
3\end{array}$ & - & $9 / 9$ & - & $\begin{array}{l}25 / 2 \\
5\end{array}$ & - & $18 / 18$ & “7” & $6 / 7$ & - & $6 / 6$ & 0.97 \\
\hline
\end{tabular}

* Dis.: discrepancies; Sco.: score; NSC: none of special cases were mentioned; missing prototypes were enclosed in quotation marks; missing special cases were underlined; erroneous answers were presented in round brackets; dashes demonstrated that a teacher's answer includes the prototypes of the corresponding quadrilateral and all its special cases.

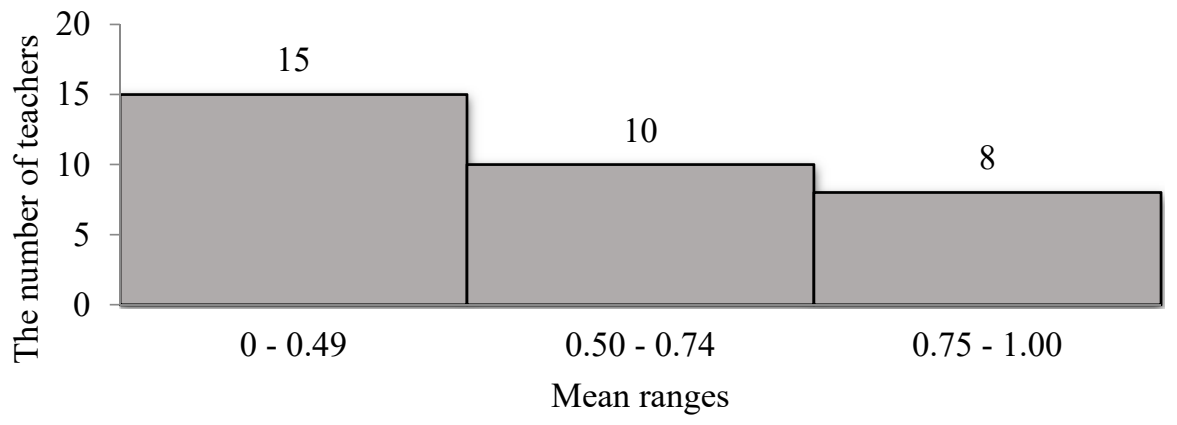

Figure 5. The distributions of mathematics teachers' mean scores in the second question

In the third question, mathematics teachers were asked to illustrate the relationship among a kite, trapezoid, parallelogram, rectangle, rhombus and square, but 2 of them did not answer this question. As demonstrated in Figure 7, there was a link between a kite and a rhombus in the referent knowledge map, but this relationship was included in only 10 teachers' knowledge maps (32\%). Additionally, a trapezoid was linked with both a rectangle and parallelogram in the referent knowledge map, yet these relationships were highlighted by only 1 teacher (3\%) and 7 teachers $(23 \%)$, respectively. Elsewhere, while there was a link between a parallelogram and rectangle in the referent knowledge map, 26 teachers (84\%) linked these quadrilaterals in their knowledge maps. While a parallelogram and rhombus were linked in the referent knowledge map, 23 teachers (74\%) included this relationship in their maps. Similarly, a link between a rectangle and square was shown in the referent knowledge map, and 23 teachers' (74\%) produced this link in their maps. The relationship between a rhombus and a square was also shown in the referent knowledge map, yet only $17(55 \%)$ teachers included this in their knowledge map. Finally, even though no link was shown between a parallelogram and square in the referent knowledge map, 10 teachers (32\%) linked these quadrilaterals. Consequently, as seen in Table 5 , while the highest similarity index between the referent knowledge map and teachers' knowledge maps was found as .86, the average was calculated as .446. Table 5 illustrates that little similarity exists between the referent knowledge map and the knowledge maps created by 17 teachers (55\%), whereas moderate similarity was seen in 13 teachers' knowledge maps $(42 \%)$. Only one teacher's knowledge map (3\%) showed a strong similarity with the referent map. 


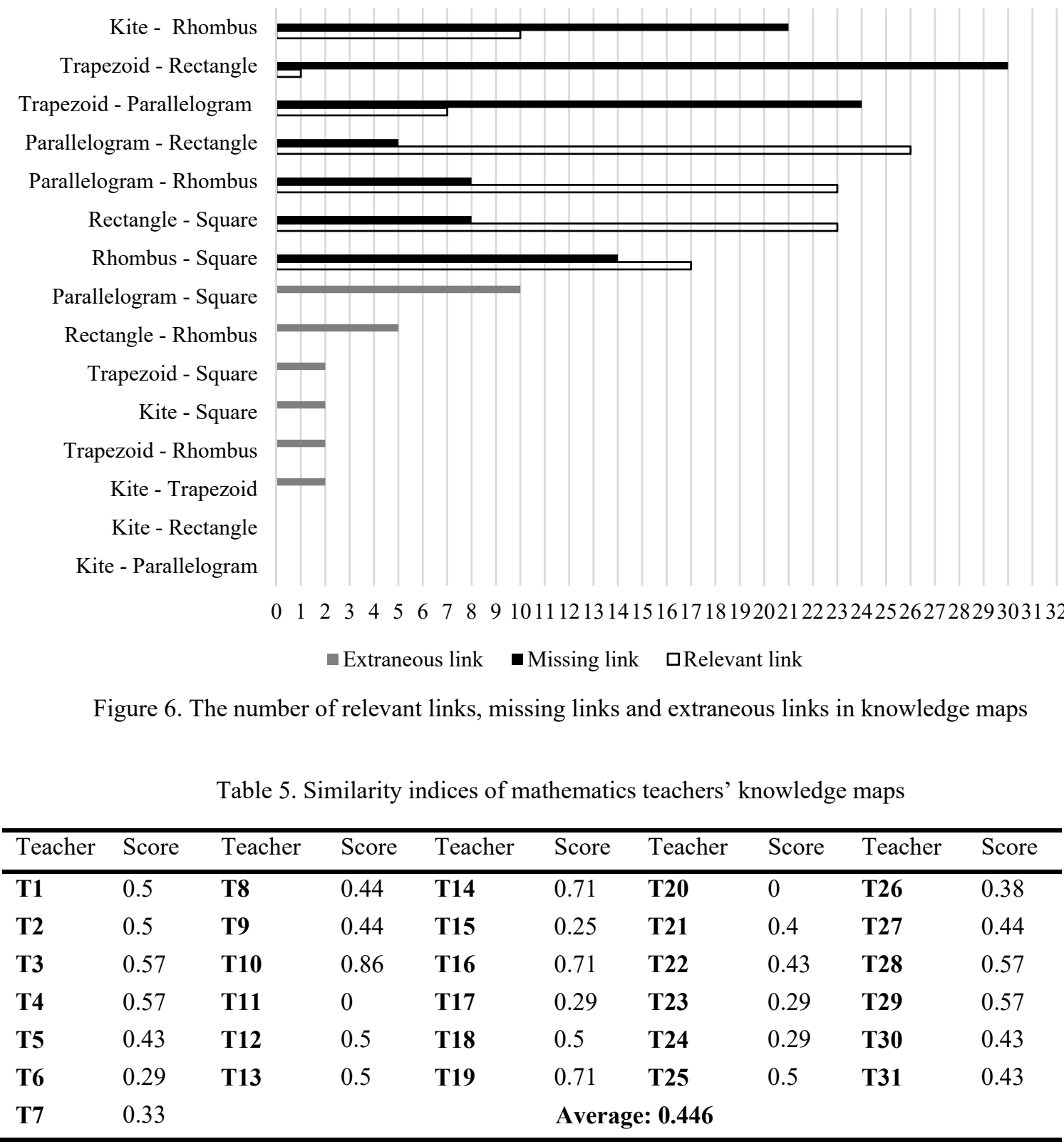

\section{Discussions and conclusions}

This study aimed to investigate how well mathematics teachers in Turkey define special types of quadrilaterals, recognize their family and make a hierarchical classification of them. We found that teachers encounter problems in defining special types of quadrilaterals, determining their family and hierarchically organizing them. To our knowledge, the number of studies exploring mathematics teachers' content knowledge of quadrilaterals is very limited, so the findings of this study are discussed in relation to a number of studies that also examined pre-service teachers' content knowledge of quadrilaterals.

The first problem was investigated concerning the definition of a kite, recognition of the kite family and demonstration of the link between a kite and a rhombus. The results of this study showed that 31 teachers $(94 \%)$ gave the correct definition of a kite while $20(60 \%)$ hierarchically defined it. Additionally, 4 teachers $(12 \%)$ determined the kite family whereas the kite-rhombus relation was revealed by only 10 teachers $(32 \%)$. Likewise, Güner and Gülten (2016) found that 36 of 50 pre-service teachers (72\%) could accurately define a kite. However, Ndlovu (2014) found that only 4 of 16 pre-service teachers gave the correct definition. In addition, Çontay and Paksu (2012) reported that 3 of 5 pre-service teachers identify the kite family. 
Similarly, primary school mathematics teachers faced challenges in defining a trapezoid, determining the trapezoid family and highlighting trapezoid-parallelogram and trapezoid-rectangle relations. In this research, all teachers could produce an accurate definition of a trapezoid, yet only $3(9 \%)$ of those were hierarchical definitions. Additionally, 4 teachers (12\%) investigated the trapezoid family. Furthermore, while one teacher (3\%) included the link between a trapezoid and rectangle in their knowledge map, the trapezoid-parallelogram relation was demonstrated by only 7 teachers (23\%). Likewise, Duatepe-Paksu et al. (2012) found that $10(22 \%)$ of 45 preservice teachers erroneously define a trapezoid whereas Ndlovu (2014) observed that 12 (75\%) of 16 pre-service teachers could give the correct definition. Moreover, Güner and Gülten (2016) reported that 32 (64\%) of 50 preservice teachers accurately define a trapezoid. On the other hand, Erdogan and Dur (2014) found that 26 (46\%) of 57 pre-service teachers could provide an accurate definition of a trapezoid. In addition, Türnüklü, Gündoğdu Alaylı et al. (2013) found that $12(33 \%)$ of 36 pre-service teachers could correctly define a trapezoid whilst Fujita and Jones $(2006 \mathrm{~b}, 2007)$ revealed that only $19(12 \%)$ of 158 pre-service teachers could do this. Regarding the hierarchical definition of a trapezoid, Karakuş and Erşen (2016) determined that 7 (12\%) of 58 pre-service teachers hierarchically define a trapezoid. Additionally, Türnüklü, Akkaş, et al. (2013) found that only 1 in 9 mathematics teachers in a study conducted in Turkey could link a trapezoid with a rectangle. While Fujita and Jones (2006b) reported that $29(23 \%)$ of 124 pre-service teachers could demonstrate the link between a trapezoid and rectangle, Erdogan and Dur (2014) observed in Turkey that only 4 (7\%) of 57 pre-service teachers include this relation in their knowledge maps. In another study conducted in Turkey, Karakuş and Erşen (2016) determined that 16 (25\%) of 58 pre-service teachers highlight the relation of trapezoid-rectangle.

However, primary school mathematics teachers performed relatively better when providing the definition of a parallelogram, recognizing the parallelogram family and presenting the links of a parallelogram-rectangle and parallelogram-rhombus. In this study, 32 teachers (97\%) accurately defined a parallelogram whilst 31 teachers (94\%) hierarchically defined a parallelogram. Additionally, 15 teachers (45\%) determined the parallelogram family whereas the relations of a parallelogram-rectangle and parallelogram-rhombus were revealed by 26 teachers (84\%) and 23 teachers (74\%), respectively. Similarly, Erşen and Karakuş (2013) detected that 6 of 6 preservice teachers could indicate the accurate definition of parallelogram while Duatepe-Paksu et al. (2012) found that $37(82 \%)$ of 45 pre-service teachers could correctly define it. In addition, Erdogan and Dur (2014) reported that $46(81 \%)$ of 57 pre-service teachers could produce a correct definition of a parallelogram whilst Ndlovu (2014) found that 12 of 16 pre-service teachers could make an accurate definition. Furthermore, Fujita and Jones (2006b, 2007) observed that $93(59 \%)$ of 158 pre-service teachers could correctly define a parallelogram whereas Güner and Gülten (2016) reported that only 20 (40\%) of 50 pre-service teachers could do this accurately. Karakuş and Erşen (2016) reported that $31(53 \%)$ of 58 pre-service teachers provide the hierarchical definition of a parallelogram. Additionally, Erdogan and Dur (2014) found that 29 (51\%) of 57 pre-service teachers recognize the parallelogram family whereas Fujita and Jones (2006a, 2007) reported that only 21 (20\%) of 105 pre-service teachers could identify the parallelogram family. Concerning the relations of a parallelogram-rectangle and parallelogram-rhombus, Erdogan and Dur (2014) determined that 53 of 57 pre-service teachers could highlight these links. On the other hand, Žilková (2015) indicated that 70 of 159 pre-service teachers could describe a parallelogram-rectangle relation, while 115 of the sample could show the relation of a parallelogram-rhombus. In addition, Okazaki and Fujita (2007) reported that $40 \%$ of 111 pre-service teachers could illustrate the relation of a parallelogram-rectangle and $41 \%$ of the sample could indicate the parallelogram-rhombus link. Moreover, Fujita and Jones (2006b) found that $43(34 \%)$ of 124 pre-service teachers could highlight the relation between a parallelogram and rectangle while only $10(8 \%)$ of the sample could associate a parallelogram with a rhombus. Furthermore, Ndlovu (2014) reported that although 5 of 16 pre-service teachers could reveal the parallelogramrectangle link, only 4 of 16 pre-service teachers indicate the parallelogram-rhombus link. Türnüklü, Akkaş, et al. (2013) also found that 3 of 9 mathematics teachers could indicate the parallelogram-rectangle relation, whereas only 2 of the sample could accurately illustrate the parallelogram-rhombus link in their knowledge maps.

All teachers in this study could accurately define a rectangle and 31 (94\%) could indicate the hierarchical definition. Furthermore, 14 teachers $(42 \%)$ investigated the rectangle family and $23(74 \%)$ included the link between a rectangle and square in their knowledge maps. Similarly, Ndlovu (2014) reported that 14 of 16 preservice teachers could provide the correct definition of a rectangle and Erşen and Karakuş (2013) observed that 5 of 6 pre-service teachers could do so. Additionally, Duatepe-Paksu et al. (2012) found that 10 (22\%) of 45 preservice teachers would erroneously define a rectangle while Brunheira and da Ponte (2015) reported that $22(39 \%)$ of 57 pre-service teachers indicate an erroneous definition. In Turkey, Erdogan and Dur (2014) reported that 39\% of 57 pre-service teachers could accurately define a rectangle and Güner and Gülten (2016) observed that only 18 (34\%) of 50 pre-service teachers could do this. Likewise, Türnüklü, Gündoğdu Alaylı et al. (2013) determined that only $33 \%$ of 36 pre-service teachers could give the correct definition of a rectangle. Elsewhere, an earlier study by Fujita and Jones (2006b, 2007) found that only 34 (26\%) of 158 pre-service teachers could correctly define a rectangle. Karakuş and Erşen (2016) reported that 42 (72\%) of 58 pre-service teachers could provide the 
hierarchical definition of a rectangle whereas Pickreign (2007) found that only 9 (22\%) of 40 pre-service teachers could do so. Erdogan and Dur (2014) found that 24 (46\%) of 57 pre-service teachers recognize the rectangle family. Regarding the rectangle-square link, Erdogan and Dur (2014) found that 54 (95\%) of 57 pre-service teachers could indicate this relation while Karakuş and Erşen (2016) detected that 49 (85\%) of 58 pre-service teachers reveal this link. Ndlovu (2014) also reported that 12 of 16 pre-service teachers highlight this relation. However, Okazaki and Fujita (2007) found that 37\% of 111 pre-service teachers illustrate this link whereas Fujita and Jones (2006b) found that 39 (31\%) of 124 pre-service teachers could indicate this relation. Additionally, Brunheira and da Ponte (2015) found that only 14 (25\%) of 57 pre-service teachers reveal the link between a rectangle and square.

Moreover, 31 teachers (94\%) correctly defined a rhombus and 26 (79\%) could do so hierarchically. Of this sample, 16 teachers (48\%) determined the rhombus family, and the rhombus-square relation was seen by 17 teachers (55\%). Likewise, Duatepe-Paksu et al. (2012) reported that $10(22 \%)$ of 45 pre-service teachers provide the erroneous definition of a rhombus whereas Ndlovu (2014) observed that 11 of 16 pre-service teachers accurately define a rhombus. In Turkey, Türnüklü, Gündoğdu Alaylı et al. (2013) found that 14 (40\%) of 36 pre-service teachers provide the correct definition of a rhombus and Güner and Gülten (2016) indicated that 21 (42\%) of 50 pre-service teachers give an accurate definition. Additionally, Erdogan and Dur (2014) determined that 19 (33.3\%) of 57 pre-service teachers reveal the correct definition of a rhombus whilst Pickreign (2007) found that only 1 $(2.5 \%)$ of 40 pre-service teachers could provide the hierarchical definition of a rhombus. Moreover, Erdogan and Dur (2014) reported that $28(49 \%)$ of 57 pre-service teachers identify the rhombus family. Concerning the relation of a rhombus-square, Erdogan and Dur (2014) reported that $52(91 \%)$ of 57 pre-service teachers include this relation in their knowledge map whilst Ndlovu (2014) determined that only 10 of 16 pre-service teachers could do so. Earlier, Okazaki and Fujita (2007) found that $28(25 \%)$ of 111 pre-service teachers indicate this relation whereas Fujita and Jones (2006b) reported that 24 (19\%) of 124 pre-service teachers could do so. In addition, Žilková (2015) indicated that 24 (15\%) of 159 pre-service teachers illustrate this relation while Türnüklü, Akkaş, et al. (2013) observed that only 2 of 9 mathematics teachers demonstrate this relation in their knowledge maps.

Finally, all mathematics teachers in this study provided an accurate definition of a square, yet 10 of them (32\%) mistakenly demonstrated the parallelogram-square relation. Similarly, Erşen and Karakuş (2013) reported that 6 of 6 pre-service teachers correctly define a square while Ndlovu (2014) found that 15 of 16 pre-service teachers gave an accurate definition. Additionally, Erdogan and Dur (2014) observed that 54 (95\%) of 57 pre-service teachers could provide the correct definition of a square whereas Brunheira and da Ponte (2015) found that 49 $(86 \%)$ of 57 pre-service teachers accurately define a square. Furthermore, Karakuş and Erşen (2016) revealed that $48(83 \%)$ of 58 pre-service teachers could give the accurate definition of a square whilst Türnüklü, Gündoğdu Alaylı et al. (2013) reported that 19 (53\%) of 36 pre-service teachers provided the correct definition. However, Fujita and Jones $(2006 \mathrm{~b}, 2007)$ reported that only $60(38 \%)$ of 158 pre-service teachers could correctly define a square while in Turkey Güner and Gülten (2016) determined that 22 (44\%) of 50 pre-service teachers could do so. Moreover, Erdogan and Dur (2014) found that 21 (37\%) of 57 pre-service teachers erroneously indicate the parallelogram-square relation.

In conclusion, the results of this study show that primary school mathematics teachers encounter challenges when defining special types of quadrilaterals, determining their family and hierarchically classifying them. Consequently, in-service trainings should be planned and implemented to enhance teachers' content knowledge of quadrilaterals. Such training should include dynamics geometry software such as Cabri Geometry and Geometer's Sketchpad. Öztoprakçı (2014) reported that the use of Geometer's Sketchpad was seen to increase Turkish pre-service teachers' performance in identifying the basic properties of quadrilaterals, defining them, exploring the relations between them and organising them hierarchically. GeoGebra software might also be used for improving mathematics teachers' knowledge in terms of defining a kite and trapezoid and identifying the kite and trapezoid family.

During such training, mathematics teachers can be asked to create two isosceles triangles whose bases are the same size, using a graphics program like Geometer's Sketchpad. They can then prompted to place the base of the triangle over another one for constructing a kite. Thereafter, they might be asked to draw the diagonals in a kite to help them to explore its properties, e.g. the diagonals are perpendicular and that one of these diagonals is both an angle bisector and a line of symmetry. Thus, once mathematics teachers can explore the fundamental properties of a kite, they will be more able to recognise the kite family. Similarly, teachers can be asked to draw a parallelogram and rectangle and then to show the diagonals. When the properties of the diagonals are examined, it can be concluded that the diagonals of a parallelogram and rectangle are not perpendicular. Hence, mathematics teachers can more readily detect that a parallelogram and rectangle are members of the kite family. Similar 
exercises with a rhombus and square and their diagonals, can help teachers to investigate the properties of their diagonals in relation to a kite and appreciate why these shapes are members of the same family.

\section{References}

Akkaş, E. N., \& Türnüklü, E. (2015). Middle school mathematics teachers' pedagogical content knowledge regarding student knowledge about quadrilaterals. Elementary Education Online, 14(2), 744-756.

Ball, D. L., Hill, H. C., \& Bass, H. (2005). Knowing mathematics for teaching: Who knows mathematics well enough to teach third grade, and how can we decide? American Educator, (Fall), 14-46.

Beins, B. C., \& McCarthy, M. A. (2011). Research methods and statistics. New Jersey, USA: Pearson Higher Education.

Brunheira, L., \& da Ponte, J. P. (2015). Prospective teachers' development of geometric reasoning through an exploratory approach. In K. Krainer \& N. Vondrova (Eds.), Proceedings of the Ninth Congress of the European Society for Research in Mathematics Education (pp. 515-521). Prague, Czech Republic: Le Centre pour la Communication Scientifique Directe. Retrieved from https://hal.archives-ouvertes.fr/hal01286995

Can, A. (2014). SPSS ile bilimsel araştırma sürecinde nicel veri analizi [Quantitative data analysis in scientific research with SPSS] (3rd ed.). Ankara, Turkey: Pegem Akademi.

Cansız-Aktaş, M. (2016). Turkish high school students' definitions for parallelograms: appropriate or inappropriate? International Journal of Mathematical Education in Science and Technology, 47(4), 583596.

Çepni, S. (2014). Araştırma ve proje çalışmalarına giriş [Introduction to research and project studies]. Trabzon, Turkey: Celepler Matbaacilik.

Cohen, J. (1960). A Coefficient of Agreement for Nominal Scales. Educational and Psychological Measurement, 20(1), 37-46. https://doi.org/10.1177/001316446002000104

Cohen, L., Manion, L., \& Morrison, K. (2013). Research methods in education (7th ed.). London, UK: Routledge.

Çontay, E. G., \& Paksu, A. D. (2012). Preservice mathematics teachers' understandings of the class inclusion between kite and square. Procedia-Social and Behavioral Sciences, 55, 782-788.

Darling-Hammond, L. (2000). Teacher quality and student achievement. Education Policy Analysis Archives, $8(1), 1-44$

DePoy, E., \& Gitlin, L. N. (2011). Introduction to research: Understanding and applying multiple strategies (4th ed.). St. Louis, Missouri, USA: Elsevier Health Sciences.

Duatepe-Paksu, A., İymen, E., \& Pakmak, G. S. (2012). How well elementary teachers identify parallelogram? Educational Studies, 38(4), 415-418.

Erdogan, E. O., \& Dur, Z. (2014). Preservice mathematics teachers' personal figural concepts and classifications about quadrilaterals. Australian Journal of Teacher Education, 39(6), 107-133.

Erşen, Z., \& Karakuş, F. (2013). Sınıf öğretmeni adaylarının dörtgenlere yönelik kavram imajlarının değerlendirilmesi [Evaluation of preservice elementary teachers' concept images for quadrilaterals]. Turkish Journal of Computer and Mathematics Education, 4(2), 124-146.

Fujita, T. (2012). Learners' level of understanding of the inclusion relations of quadrilaterals and prototype phenomenon. The Journal of Mathematical Behavior, 31(1), 60-72.

Fujita, T., \& Jones, K. (2006a). Primary trainee teachers' knowledge of parallelograms. Proceedings of the British Society for Research into Learning Mathematics, 26(2), 25-30.

Fujita, T., \& Jones, K. (2006b). Primary trainee teachers' understanding of basic geometrical figures in Scotland. In Proceedings 30th Conference of the International Group for the Psychology of Mathematics Education (Vol. 3, pp. 129-136). Prague, Czech Republic: Psychology of Mathematics Education. Retrieved from http://eprints.soton.ac.uk/41247/1/Fujita_Jones_PME30_2006.pdf

Fujita, T., \& Jones, K. (2007). Learners' understanding of the definitions and hierarchical classification of quadrilaterals: towards a theoretical framing. Research in Mathematics Education, 9(1\&2), 3-20.

Goldhaber, D. D., \& Brewer, D. J. (2000). Does teacher certification matter? High school teacher certification status and student achievement. Educational Evaluation and Policy Analysis, 22(2), 129-145.

Goldsmith, T. E., Johnson, P. J., \& Acton, W. H. (1991). Assessing Structural Knowledge. Journal of Educational Psychology, 83(1), 88-96.

Güner, P., \& Gülten, D. Ç. (2016). Pre-service primary mathematic teachers'skills of using the language of mathematics in the context of quadrilaterals. International Journal on New Trends in Education \& Their Implications, 7(1), 13-27.

Gwet, K. L. (2014). Handbook of inter-rater reliability: the definitive guide to measuring the extent of agreement among raters (4th ed.). Gaithersburg, USA: Advanced Analytics, LLC. 
Hill, H. C., Blunk, M. L., Charalambous, C. Y., Lewis, J. M., Phelps, G. C., Sleep, L., \& Ball, D. L. (2008). Mathematical knowledge for teaching and the mathematical quality of instruction: An exploratory study. Cognition and Instruction, 26(4), 430-511.

Josefsson, M. (2013). Characterizations of trapezoids. Forum Geometricorum, 13, 23-35.

Karakuş, F., \& Erşen, Z. B. (2016). Sınıf öğretmeni adaylarının bazı dörtgenlere yönelik tanımlama ve sinıflamalarının incelenmesi [Examining pre-service primary school teachers' definitions and classifications towards quadrilaterals]. Karaelmas Journal of Educational Sciences, 4(1), 38-49.

Kudikyala, K., \& Vaughn, R. (2004). Understanding software requirements using Pathfinder networks. Cross Talk: The Journal of Defense Software Engineering, 17(5), 16-25.

Landis, J. R., \& Koch, G. G. (1977). The measurement of observer agreement for categorical data. Biometrics, 33(1), 159-174. https://doi.org/10.2307/2529310

Marks, R. (1990). Pedagogical content knowledge: From a mathematical case to a modified conception. Journal of Teacher Education, 41(3), 3-11.

Morris, A. K., Hiebert, J., \& Spitzer, S. M. (2009). Mathematical knowledge for teaching in planning and evaluating instruction: What can preservice teachers learn. Journal for Research in Mathematics Education, 40(5), 491-529.

Mullis, I. V. S., Martin, M. O., Foy, P., \& Hooper, M. (2016). TIMSS 2015 international results in mathematics. Chestnut Hill, MA, USA: Boston College, TIMSS \& PIRLS International Study Center. Retrieved from http:/timssandpirls.bc.edu/timss2015/international-results/

Ndlovu, M. (2014). Pre-service teachers' understanding of geometrical definitions and class inclusion: an analysis using the Van Hiele model. In L. G. Chova, A. L. Martínez, \& I. C. Torres (Eds.), INTED2014 Proceedings (pp. 6642-6652). Valencia, Spain: International Academy of Technology, Education and Development. $\quad$ Retrieved from https://www.researchgate.net/profile/Mdu_Ndlovu/publication/260853961_PRESERVICE TEACHER S'_UNDERSTANDING_OF_GEOMETRICAL_DEFINITIONS_AND_CLASS_INCLUSION_AN_A NĀLYSIS_USING_THE_VĀN_HIELE_MODEL/links/00b4953282f2ä70490000000.pdf

Okazaki, M., \& Fujita, T. (2007). Prototype phenomena and common cognitive paths in the understanding of the inclusion relations between quadrilaterals in Japan and Scotland. In J. H. Woo, H. C. Lew, K. S. Park, \& D. Y. Seo (Eds.), Proceedings of the 31st Conference of the International Group for the Psychology of Mathematics Education (Vol. 4, pp. 41-48). Seoul, South Korea: Psychology of Mathematics Education. Retrieved from http://files.eric.ed.gov/fulltext/ED499418.pdf

Öztoprakç1, S. (2014). Pre-service middle school mathematics teachers' understanding of quadrilaterals through the definitions and their relationships (Doctoral Dissertation). Middle East Technical University, Ankara, Turkey.

Pickreign, J. (2007). Rectangles and rhombi: how well do preservice teachers know them?. Issues in the Undergraduate Mathematics Preparation of School Teachers, 1. Retrieved from http://eric.ed.gov/?id=EJ835492

Popovic, G. (2012). Who is this trapezoid, anyway? Mathematics Teaching in the Middle School, 18(4), 196-199.

Sarwar, G. S., \& Trumpower, D. L. (2015). Effects of conceptual, procedural, and declarative reflection on students' structural knowledge in physics. Educational Technology Research and Development, 63(2), 185-201.

Shir, K., \& Zaslavsky, O. (2001). What constitutes a (good) definition? The case of a square. In M. van den Heuvel-Panhuizen (Ed.), Proceedings of the 24th annual conference of the International Group for the Psychology of Mathematics Education (Vol. 4, pp. 161-168). Utrecht, The Netherlands: Psychology of Mathematics Education. Retrieved from http://files.eric.ed.gov/fulltext/ED466950.pdf

Shulman, L. S. (1986). Those who understand: Knowledge growth in teaching. Educational Researcher, 15(2), 4-14.

T.C. Millî Eğitim Bakanlığı Talim ve Terbiye Kurulu Başkanlığı. (2013). Ortaokul matematik dersi (5, 6,7 ve 8. sinıflar) öğretim programı [Middle school mathematics curriculum (Grade 5, 6, 7, 8)]. Retrieved from http://ttkb.meb.gov.tr/dosyalar/programlar/ilkogretim/matematik_5-8.rar

The National Council of Teachers of Mathematics. (2000). Executive summary: principles and standards for school mathematics (Vol. 1). Reston, VA, USA: National Council of Teachers of Mathematics. Retrieved from http://www.nctm.org/uploadedFiles/Standards_and_Positions/PSSM_ExecutiveSummary.pdf

Türnüklü, E., Akkaş, E. N., \& Alayl, F. G. (2013). Mathematics teachers' perceptions of quadrilaterals and understanding the inclusion relations. In B. Ubuz, C. Haser, \& M. A. Mariotti (Eds.), Proceedings of 8th Congress of the European Society for Research in Mathematics Education (pp. 705-714). Ankara, Turkey: Middle East Technical University. Retrieved from http://cerme8.metu.edu.tr/wgpapers/WG4/WG4_Akkas.pdf 
Türnüklü, E., Gündoğdu Alaylı, F., \& Akkaş, E. N. (2013). Investigation of prospective primary mathematics teachers' perceptions and images for quadrilaterals. Educational Sciences: Theory and Practice, 13(2), $1225-1232$.

Usiskin, Z., Griffin, J., Witonsky, D., \& Willmore, E. (2008). The classification of quadrilaterals: a study in definition. Charlotte, NC: Information Age Publishing.

Žilková, K. (2015). Misconceptions in pre-service primary education teachers about quadrilaterals. Journal of Education, Psychology and Social Sciences, 3(1), 30-37. 